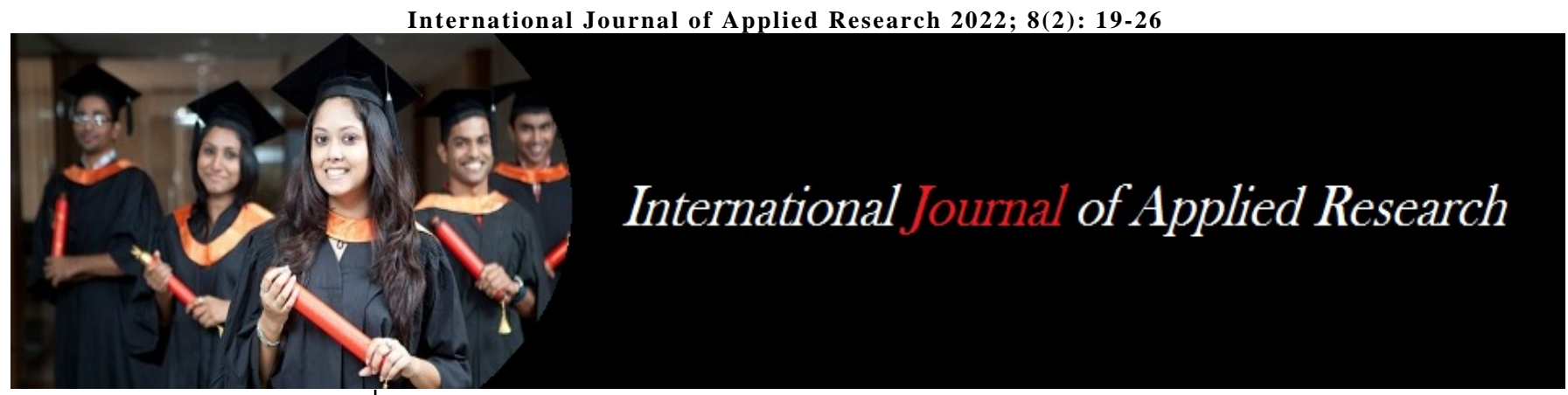

ISSN Print: $2394-7500$

ISSN Online: 2394-5869

Impact Factor: 8.4

IJAR 2022; 8(2): 19-26

www.allresearchjournal.com

Received: 11-12-2021

Accepted: 14-01-2022

Swathi G

Data Coding Specialist,

Labcorp Drug Development,

Bangalore, Karnataka, India

Dr. Puvaneswari Kangaraj

Professor and HOD,

Department of Medical

Surgical Nursing and Research,

Narayana Hrudayalaya

College of Nursing,

Bangalore, Karnataka, India

Corresponding Author:

Dr. Puvaneswari Kanagaraj

Professor and HOD,

Department of Medical

Surgical Nursing and Research

Narayana Hrudayalaya

College of Nursing,

Bangalore, Karnataka, India

\section{Effectiveness of aromatherapy on post-operative pain and discomfort among orthopaedic patients: Experimental study}

\author{
Swathi G and Dr. Puvaneswari Kangaraj
}

DOI: $\underline{\text { https://doi.org/10.22271/allresearch.2022.v8.i2a.9378 }}$

\begin{abstract}
Introduction: Post-operative pain and discomfort are unavoidable after orthopaedic surgeries. Effective pain management is an essential component of post-operative care. Aromatherapy is one of the popular complementary therapies used with pain management in various medical conditions.

Methods: A quantitative research approach with the true experimental study with pre-test post-test control group design was adopted with sixty patients (Control -30, Experimental-30) who were selected using a simple random sampling technique. The data was collected using the baseline and clinical variables, numerical pain scale, and discomfort intensity scale.

Results: In the experimental group, the mean and S.D of pain on the 1 st day was $7.97 \pm 1.38$ and in the post-test was $6.13+1.74$. And the 3rd-day pre-test was $2.70 \pm 1.51$ and the post-test was $1.53 \pm 1.14$. And the mean and S.D of discomfort on the 1 st day was $19.7+4.7$ and in the post-test was $14.07+3.93$. And 3rd-day pre-test was $2.70 \pm 1.51$ and post-test was $1.53 \pm 1.14$ in the experimental group. The repeated measures of ANOVA indicated that there was within the group difference of pain $(\mathrm{F}=314.7, \mathrm{p}=0.001)$, and discomfort $(\mathrm{F}=23.21, \mathrm{p}=0.001)$ scores were decreased over time (pre day1- post day3) in the experimental group.

Conclusion: This present study showed a significant positive effect of aromatherapy in the reduction of pain and discomfort among orthopaedic surgical patients.
\end{abstract}

Keywords: Postoperative pain, discomfort, orthopaedic surgery, aromatherapy, complementary therapy, lavender oil

\section{Introduction}

Pain and discomfort are unpleasant sensations with uneasiness. It is inevitable with a postsurgical period ${ }^{[1]}$. Management of post-operative pain is a challenge for the health care team [2]. Perioperative pain management is an important public health concern because approximately 240 million patients undergo major surgery annually, worldwide [3] Orthopaedic surgery is one of the most painful and discomfortable surgeries ${ }^{[4]}$. The common orthopaedic surgical procedures include hip and knee arthroplasties, replacement, extremity fracture procedures using internal and external fixators. In 2017, approximately 22.3 million ortho surgeries were done globally ${ }^{[5]}$. As the life span of the world's population continues to rise, experts predict that there will be a dramatic increase in the number of orthopaedic surgeries required for knee or hip replacements and surgeries to stabilize, align, and repair bone fractures ${ }^{[6]}$.

Acute pain after orthopaedic surgery should be anticipated and its treatment should be a part of every anesthetic plan ${ }^{[7]}$. If this pain is not adequately controlled, it can interfere with effective rehabilitation and skeletal healing, resulting in significant loss of bone and muscle mass, and ultimately leading to the development of chronic skeletal pain ${ }^{[8]}$. Poorly controlled postoperative pain is associated with impaired quality of life ${ }^{[9,10]}$, increased morbidity, delayed recovery time ${ }^{[11]}$, prolonged duration of opioid use, and higher healthcare costs. In addition, the presence and intensity of acute pain during or after surgery is predictive of the development of chronic pain ${ }^{[12]}$. Postoperative pain was reported to affect activities of daily living adversely at 3 and 12 months post-discharge in approximately a quarter of patients who had inpatient orthopaedic surgery ${ }^{[13]}$ and at 1-year post-procedure in nearly a one third of patients who had outpatient knee arthroscopy ${ }^{[14]}$. 
Routine pain assessment is a cornerstone for providing safe, effective, and individualized pain management ${ }^{[15]}$.

Thorough knowledge of pain mechanisms is essential for ineffective pain control management along with an accurate therapy plan, which very often involves a multimodal approach.2 Analgesic medications and techniques are safe and effective in the management of postoperative pain 1 but they can have adverse effects too. Narcotic analgesics have general side effects such as respiratory problems, sedation, nausea, vomiting, symptoms of tolerance, or a withdrawal syndrome in patients. Using non-pharmacological methods as a complement rather than alternative interventions is recommended ${ }^{[16]}$.

Since the times of the Egyptians, essential oils have been formally documented in use. Aromatherapy (AT) is recently used in the perianesthetic period ${ }^{[17]}$. It is a complementary therapy that relies on the use of essential oils extracted from plants and flowers. The common extracts include peppermint, lavender, chamomile, eucalyptus, and rosemary. It can be administered through inhalation, topical applications ${ }^{[18]}$. In recent years lavender has been studied on postoperative pain, sleep, quality of life, anxiety, etc. for its sedative, anxiolytic, antidepressant, antispasmodic, antibacterial, and analgesic properties ${ }^{[19,20]}$. Considering the importance of managing the pain and discomfort for ortho surgical patients, this paper aims at studying the effect of aromatherapy on postoperative pain and discomfort among orthopaedic patients.

Objectives of the Study: The objectives of the study were

- To assess the effectiveness of aromatherapy on pain and discomfort among post- operative orthopaedic patients

- To determine the association between the preinterventional pain and discomfort with baseline and clinical variables.

\section{Methods}

A true experimental study comprising of pre-test post-test control group design was adopted for this study. The study setting was a tertiary care orthopaedic hospital in Bangalore which was 100 bedded. The sample size was calculated by comparison of means of a similar study ${ }^{[21]}$ using the belowmentioned formula.

$$
n=\frac{\left(z_{1-\frac{\beta}{2}}+z_{1-\beta}\right)^{2}\left(S_{1}^{2}+S_{2}^{2}\right)}{\left(\mu_{1}-\mu_{2}\right)^{2}}
$$

The sample size was calculated as 30 in each group (Experimental-30 and Control-30). The sample were selected randomly allocated to the experimental and control group using a simple random sampling technique. The inclusion criteria for the sample were patients who complained of pain and discomfort. The exclusion criteria were patients who have respiratory diseases, upper respiratory tract infections, asthma, and patients who were allergic to lavender oil, dust, drugs.

The investigator has adopted Ludwig Von Bertalanffyes (1968) General system theory for the conceptual framework. The validated questionnaire consisted of 4 sections of assessment namely Section - I Baseline variables, Section II - Clinical variables, Section - III- Numerical pain scale, and Section - IV Discomfort intensity scale. The section - I the baseline variables included were age, gender, marital status, education, monthly income, occupation, habits, previous history of hospitalization, previous history of surgery, and use of pain medication. Section -II the clinical variables included were Pulse, blood pressure, and respiration. Section - III The Numerical pain scale varies from 0-10 which is interpreted as $0=$ No pain, $1-3=$ Mild pain (Nagging, Annoying, Interfering little with ADL'S), $4-6=$ Moderate pain (Interferes significantly with ADL'S) and 7 10 = Severe pain (Disabling, Unable to perform ADL'S). Section IV- Discomfort intensity scale which is prepared by the researcher consists of six components like Sleeplessness, Tingling sensation, Difficulty in position change, Difficulty to talk, and Difficulty to eliminate with a maximum score of 30. It was interpreted as mild discomfort with a score between 1-10, moderate discomfort with a score between 11-20, and severe discomfort with a score between 21-30. The tool was validated by 8 experts including 4 Orthopaedicians. The CVI was 0.98 . The reliability of the Discomfort Intensity Scale was 0.79. Ethical clearance from the Institutional Ethics Committee and written informed consent from the participants were obtained before the data collection. The intervention protocol and the data collection were performed by the investigator which is explained in Table -1 . The investigator has done the pre-test on 1 st, $2^{\text {nd }}$ and 3rd Post-operative day, and the post-test were done on 2nd, 3rd, and 4th post-operative day.

The data were analyzed by the use of Descriptive statistics (Mean, Frequency, and Standard Deviation) and Inferential statistics (Repeated measure ANOVA, independent t-test using SPSS 22.

Table 1: Intervention protocol and data collection

\begin{tabular}{|c|c|c|c|c|}
\hline Group & Days & Pretest & Treatment & Post test \\
\hline \multirow{4}{*}{ Experimental } & $\begin{array}{c}\text { POD '1' } \\
\text { POD '2' } \\
\text { POD '3' }\end{array}$ & $\begin{array}{c}\text { Pain and discomfort } \\
\text { assessment at evening } \\
\text { before treatment }\end{array}$ & $\begin{array}{c}\text { Aromatherapy with two drops of lavender } \\
\text { oil (0.1 cc per drop with 100\% } \\
\text { concentration) instilled over the pillow } \\
\text { cover and the top sheet by evening for 3 } \\
\text { consecutive days. }\end{array}$ & $\begin{array}{c}\text { Pain and discomfort assessment } \\
\text { at morning on 3 consecutive days } \\
\text { (POD '2', POD '3',POD '4') }\end{array}$ \\
\hline Control & $\begin{array}{c}\text { POD '1' } \\
\text { POD '2' } \\
\text { POD '3' }\end{array}$ & $\begin{array}{c}\text { Pain and discomfort } \\
\text { assessment at evening } \\
\text { before treatment }\end{array}$ & $\begin{array}{c}\text { Placebo intervention- Instilled two drops of } \\
\text { distilled water on the pillow cover and the } \\
\text { top sheet by evening for 3 consecutive days. }\end{array}$ & $\begin{array}{c}\text { Pain and discomfort assessment } \\
\text { at morning on 3 consecutive days } \\
\text { (POD '2', POD '3',POD '4') }\end{array}$ \\
\hline
\end{tabular}

\section{Results}

1. Findings related to the frequency and percentage distribution of baseline and clinical variables:

Table 2 depicts that in the experimental group majority of the patients $11(36.7 \%)$ were adults below 30 years of age and in the control group majority $13(43.3 \%)$ of them were between 31-45 years of age. The majority of them were males and married in both groups. Based on the educational status most of them were graduates i.e. 14 (36.7\%) and $12(40 \%)$ in both the experimental and control group 
respectively. Based on the distribution of the monthly income of the patients in the experimental group, the majority of the patients $10(35.3 \%)$ income was $>20,000$ rupees per month, and in the control group majority 14 (46.7\%) of their income was $10,001-20,000$ rupees per month.

On the aspect of occupation, almost half of the participants (50\%) were sedentary workers in both the groups and also very few 4(13.3\%), 2(6.7\%) were heavy workers in the experimental and control group. Regarding the type of surgery in the experimental group, more than half of the patients 15(53.3\%) underwent open reduction and internal fixation and $8(26.7 \%)$ had external fixation. Similarly in the control group also a majority of the patients $14(46.7 \%)$ underwent open reduction and internal fixation and $11(36.7 \%)$ had external fixation. Around $80 \%$ of them had no history of hospitalization in both groups. And only 6.7\% in experimental and $20 \%$ in control had previous surgery. Based on the distribution of habits in the experimental group, majority of the patients reported 15(50\%) no bad habits, only a few 6(20\%) used alcohol alone and 6(20\%) used tobacco products with alcohol. In the control group also $18(60 \%)$ did not have any bad habits and only a few 2(6.7\%) were using tobacco products and alcohol. In the experimental, all patients were on tramadol, and in control, $86.7 \%$ were with tramadol and $13.3 \%$ were with paracetamol.

The frequency and percentage distribution of the clinical variables were reported as a majority of them had a pulse rate range of 76-85 beats/min, respiratory rate range of 21$25 \mathrm{breath} / \mathrm{min}$, and systolic blood pressure between 100-110 $\mathrm{mmHg}$ in both the groups.

Table 2: Frequency and percentage distribution of post-operative orthopaedic patients

\begin{tabular}{|c|c|c|c|c|c|}
\hline \multirow{2}{*}{ S. No } & \multirow[t]{2}{*}{ Baseline variables } & \multicolumn{2}{|c|}{ Experimental group } & \multicolumn{2}{|c|}{ Control group } \\
\hline & & Frequency & Percentage $\%$ & Frequency & Percentage $\%$ \\
\hline & & \multicolumn{2}{|c|}{ Age in years } & & \\
\hline \multirow{5}{*}{1.} & a) $\leq 30$ & 11 & $36.70 \%$ & 6 & $20 \%$ \\
\hline & b) $31-45$ & 9 & $30 \%$ & 13 & $43.30 \%$ \\
\hline & c) $46-60$ & 5 & $16.70 \%$ & 6 & $20 \%$ \\
\hline & d) $61-75$ & 5 & $16.70 \%$ & 5 & $16.70 \%$ \\
\hline & & & Gender & & \\
\hline \multirow{3}{*}{2.} & a) Male & 21 & $70 \%$ & 17 & $56.70 \%$ \\
\hline & b) Female & 9 & $30 \%$ & 13 & $43.30 \%$ \\
\hline & \multicolumn{5}{|c|}{ Education } \\
\hline \multirow{9}{*}{3.} & a) Graduate & 14 & $36.70 \%$ & 12 & $40 \%$ \\
\hline & b) Post graduate & 0 & 0 & 2 & $6.70 \%$ \\
\hline & c) Intermediate/high & & & & \\
\hline & d) Secondary school/PUC & 4 & $13.30 \%$ & 4 & $13.30 \%$ \\
\hline & e) High school & 2 & $6.70 \%$ & 4 & $13.30 \%$ \\
\hline & f) Middle education & 2 & $6.70 \%$ & 1 & $3.30 \%$ \\
\hline & g) Primary education & 5 & $16.70 \%$ & 3 & $10 \%$ \\
\hline & h) Illiterate & 3 & $10 \%$ & 4 & $13.30 \%$ \\
\hline & \multicolumn{5}{|c|}{ Marital status } \\
\hline \multirow{4}{*}{4.} & a) Married & 21 & $70 \%$ & 23 & $73.30 \%$ \\
\hline & b) Unmarried & 8 & $26.70 \%$ & 6 & $16.70 \%$ \\
\hline & c) Widow & 1 & $3.30 \%$ & 1 & $3.30 \%$ \\
\hline & d) Divorced & 0 & 0 & 1 & $3.30 \%$ \\
\hline & & & thly income in rupees & & \\
\hline \multirow{4}{*}{5.} & a) $>20,0001$ & 10 & $35.30 \%$ & 8 & $26.70 \%$ \\
\hline & b) $10,001-20,000$ & 7 & $23.30 \%$ & 14 & $46.70 \%$ \\
\hline & c) $5,001-10,000$ & 4 & $13.30 \%$ & 2 & $6.70 \%$ \\
\hline & d) $<5,000$ & 9 & $30 \%$ & 6 & $20 \%$ \\
\hline \multirow{4}{*}{6.} & \multicolumn{5}{|c|}{ Occupation } \\
\hline & a) Sedentary worker & 15 & $50 \%$ & 17 & $56.70 \%$ \\
\hline & b) Moderate worker & 11 & $36.70 \%$ & 11 & $36.70 \%$ \\
\hline & c) Heavy worker & 4 & $13.30 \%$ & 2 & $6.70 \%$ \\
\hline \multirow{5}{*}{7.} & \multicolumn{5}{|c|}{ Type of surgery } \\
\hline & a)Open reduction and internal fixation & 15 & $53.30 \%$ & 14 & $46.70 \%$ \\
\hline & b) Total knee replacement & 5 & $16.70 \%$ & 3 & $10 \%$ \\
\hline & c) Total hip replacement & 1 & $3.30 \%$ & 2 & $6.70 \%$ \\
\hline & d) External fixator & 8 & $26.70 \%$ & 11 & $36.70 \%$ \\
\hline \multirow{4}{*}{8.} & \multicolumn{5}{|c|}{ Previous history of hospitalization } \\
\hline & a)Yes & 5 & $16.70 \%$ & 6 & $20 \%$ \\
\hline & b)No & 25 & $83.30 \%$ & 24 & $80 \%$ \\
\hline & \multicolumn{5}{|c|}{ Previous history of surgery } \\
\hline \multirow{2}{*}{9.} & a)Yes & 2 & $6.70 \%$ & 6 & $20 \%$ \\
\hline & b)No & 28 & $93.30 \%$ & 24 & $80 \%$ \\
\hline 10. & & & Habits & & \\
\hline
\end{tabular}


2. Findings related to the effectiveness of aromatherapy on postoperative pain and discomfort among the experimental and control group

Figures 1 to 4 illustrated the level of pain and discomfort among both the experimental and control group. Findings showed a greater reduction of pain and discomfort after aromatherapy. Table -3 To understand the effectiveness of Aromatherapy on post-operative pain and discomfort among the experimental group the repeated measures of ANOVA was used. The results indicated that there was a difference ( $F=314.7, p=0.001)$ within the group, which means that postoperative pain scores were decreased over time (pre day1- post day3). Similarly for discomfort also there was a difference $(\mathrm{F}=23.21, \mathrm{p}=0.001)$ within the group which means that post-operative discomfort scores were decreased over time (pre day1- post day3). Hence, the null hypothesis $\mathrm{H} 01$ was rejected at a 0.001 level of significance.
Table 4 To understand the effectiveness of Aromatherapy on post-operative pain and discomfort between the experimental group and control group was analysed using repeated measures of ANOVA. There was a significant overall difference between the experimental and control groups $(F=18.365, p=0.001)$, this indicated that the control group had significantly higher post-operative pain compared to an experimental group. Similarly, for post-operative discomfort, there was a significant overall difference between the experimental and control groups $(F=21.298, p=0.001)$, this indicated that the control group had significantly higher postoperative discomfort compared to an experimental group. Hence the null hypothesis H02 was rejected at a 0.001 level of significance.

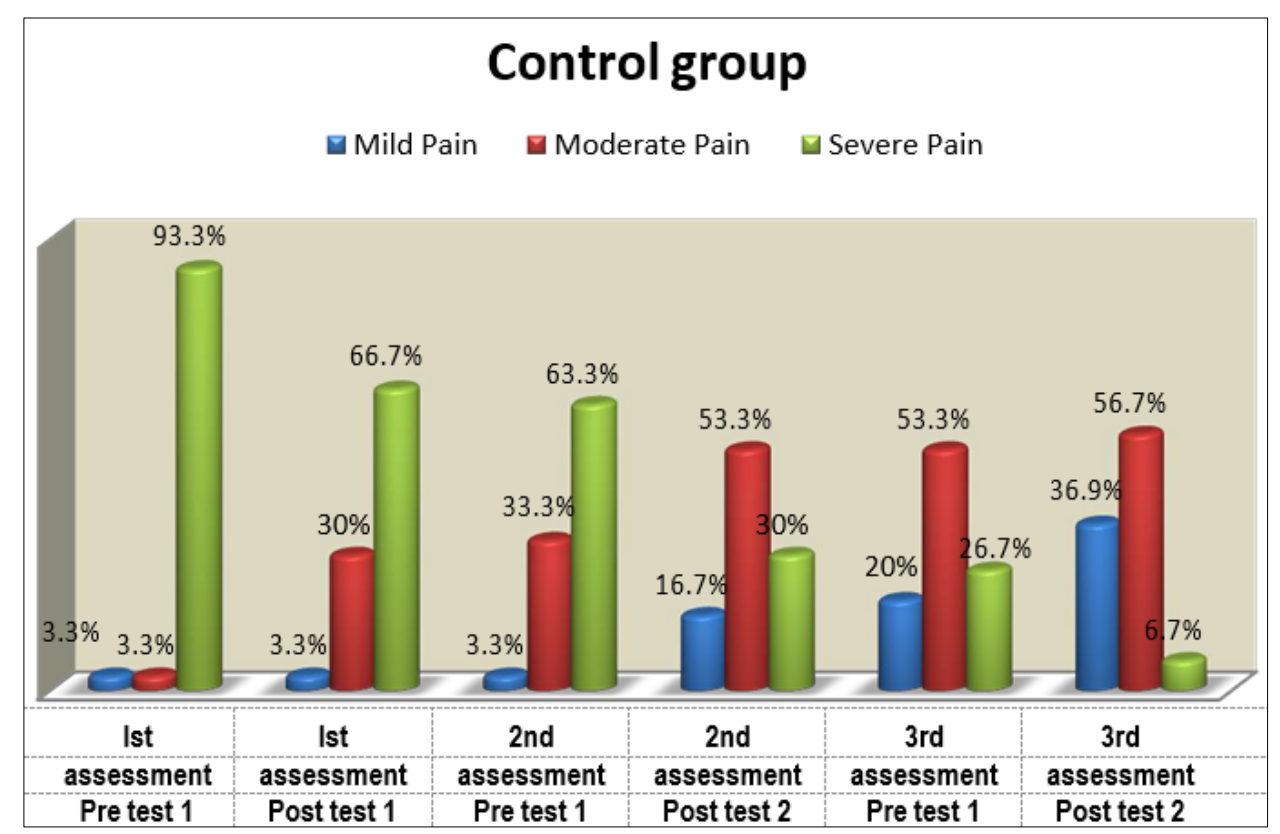

Fig 1: Frequency and percentage distribution of pain in the control group

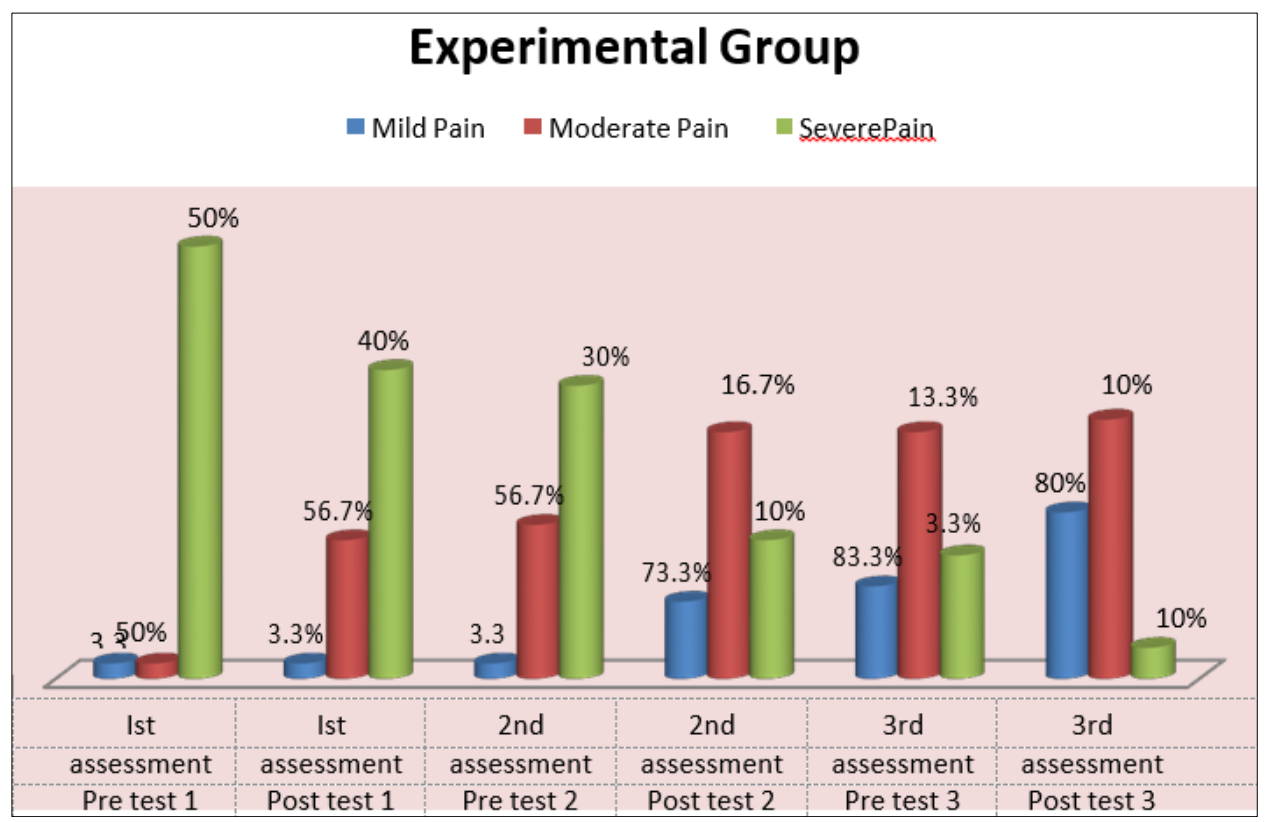

Fig 2: Frequency and percentage distribution of pain in the experimental group 


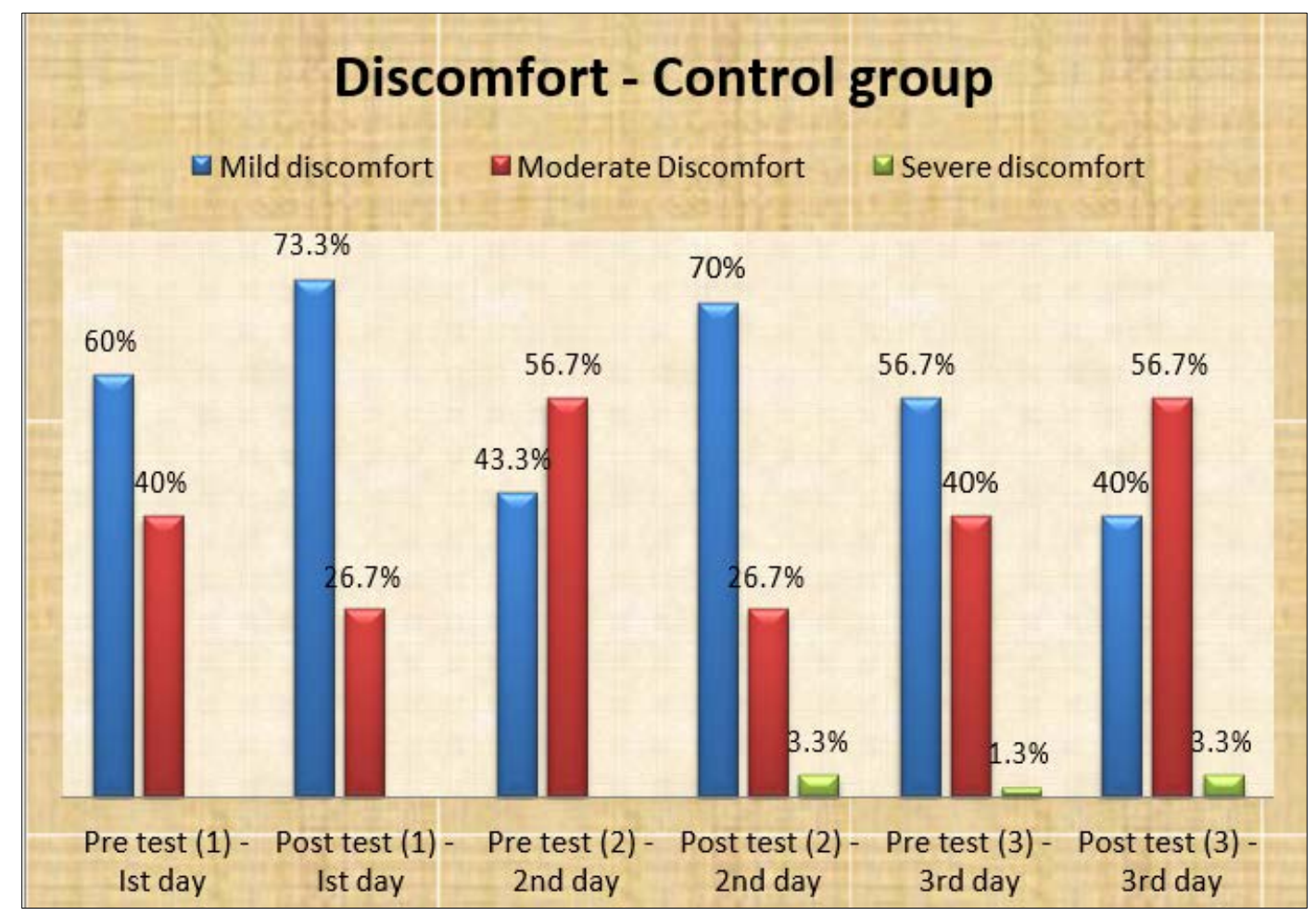

Fig 3: Frequency and percentage distribution of discomfort in the control group

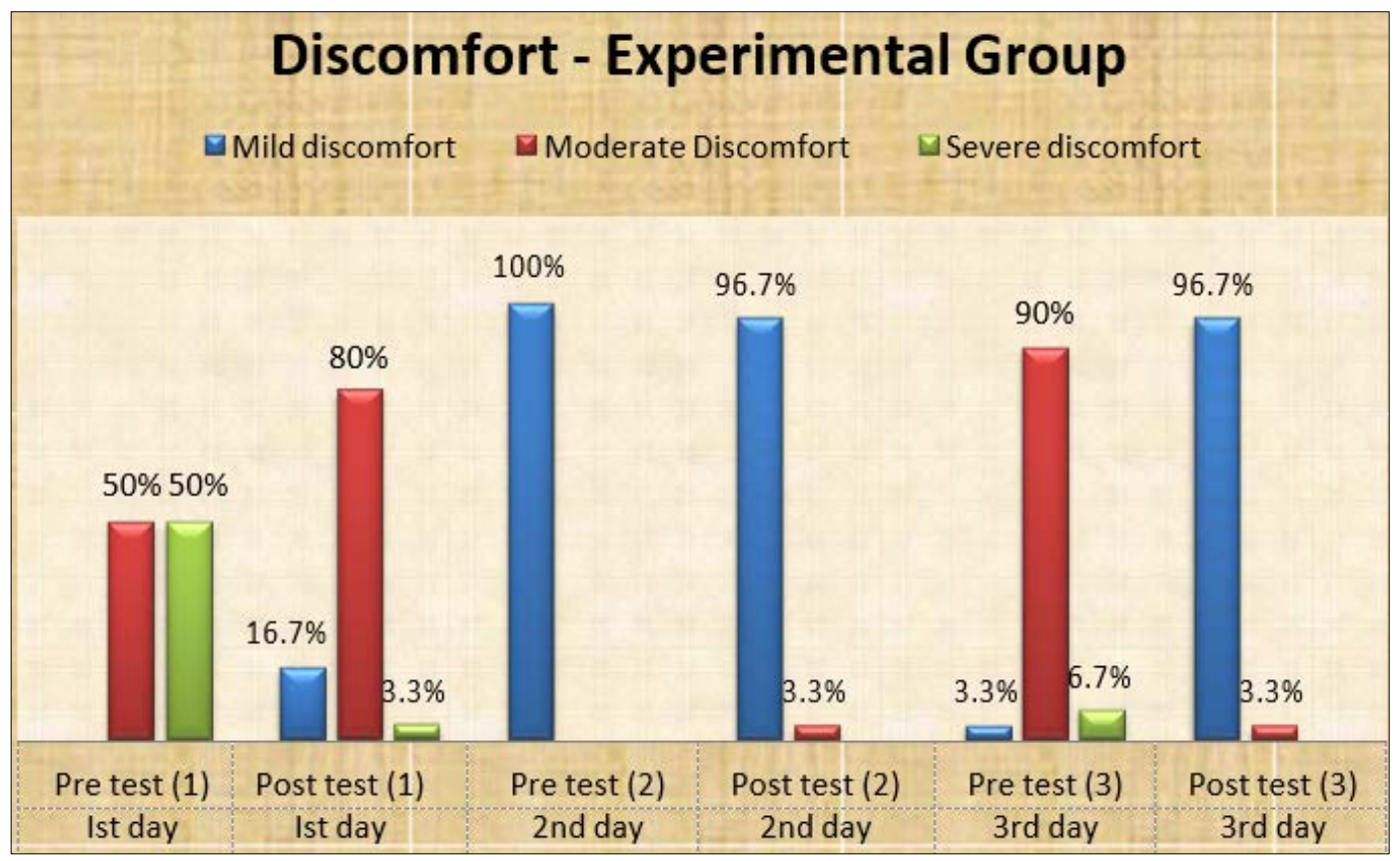

Fig 4: Frequency and percentage distribution of discomfort in the experimental group

Table 3: Effectiveness of aromatherapy in pain and discomfort among post- operative orthopaedic patients $\mathrm{N}=30$

\begin{tabular}{|c|c|c|c|c|}
\hline Day & Day1 & Day2 & Day3 & F-value(P) \\
\hline & \multicolumn{4}{|c|}{ Pain Mean \pm SD } \\
\hline Pre interventional & $7.97+1.38$ & $5.27 \pm 1.86$ & $2.70+1.51$ & 314.7 \\
\hline \multirow[t]{2}{*}{ post interventional } & $6.13+1.74$ & $3.4+1.55$ & $1.53+1.14$ & $(0.001)^{*}$ \\
\hline & \multicolumn{4}{|c|}{ Discomfort Mean+ SD } \\
\hline Pre interventional & $19.7+4.7$ & $10.67+3.4$ & $3.27 \pm 2.13$ & 23.21 \\
\hline Post interventional & $14.07+3.93$ & $5.73+2.54$ & $1.93+0.33$ & $(0.001)^{*}$ \\
\hline
\end{tabular}

\footnotetext{
*= Significant at $\mathrm{p}=0.001$ level**= Non significant
} 
Table 4: Effectiveness of aromatherapy in-pain and discomfort among post-operative orthopaedic patients between experimental and control-group. N1=30, N2=30

\begin{tabular}{|c|c|c|c|c|c|}
\hline & Group & Day1 & Day2 & Day3 & Between the group F-value (P) \\
\hline \multirow{2}{*}{ Pre interventional pain } & \multirow{2}{*}{$\begin{array}{l}\text { Experimental } \\
\text { Control }\end{array}$} & $8.43+1.69$ & $6.67+1.6$ & $5.07+1.78$ & \\
\hline & & $8.43+1.69$ & $6.67+1.6$ & $5.07+1.78$ & 18.365 \\
\hline \multirow{2}{*}{ Pre interventional pain } & \multirow{2}{*}{$\begin{array}{l}\text { Experimental } \\
\text { Control }\end{array}$} & $6.13+1.74$ & $3.4+1.55$ & $1.53+1.14$ & $(0.001) *$ \\
\hline & & $6.90+1.77$ & $5.37 \pm 1.63$ & $4.1+1.85$ & \\
\hline \multirow{2}{*}{$\begin{array}{l}\text { Pre interventional } \\
\text { discomfort }\end{array}$} & \multirow{2}{*}{$\begin{array}{l}\text { Experimental } \\
\text { Control }\end{array}$} & $19.7+4.7$ & $10.67+3.5$ & $3.27+2.1$ & 21.298 \\
\hline & & $21.73+2.64$ & $15.7+3.48$ & $10.30+4.69$ & $(0.001)^{*}$ \\
\hline \multirow{2}{*}{$\begin{array}{c}\text { Pre interventional } \\
\text { discomfort }\end{array}$} & \multirow{2}{*}{$\begin{array}{l}\text { Experimental } \\
\text { Control }\end{array}$} & $14.07 \pm 3.9$ & $5.73+2.55$ & $1.93+0.331$ & \\
\hline & & $17.9+3.7$ & $8.47+5.05$ & $17.47+3.45$ & \\
\hline
\end{tabular}

3. Association between the pre interventional pain and discomfort with baseline and clinical variables of post-operative orthopaedic patients

There was a significant association between gender $(\mathrm{t}=2.7$, $\mathrm{df}=28, \mathrm{p}=0.11$ ) and post- operative pain and also sedentary worker $(\mathrm{t}=2.485, \mathrm{df}=28, \mathrm{p}=0.19)$ with post-operative discomfort. There was no association found with other variables. Hence H03 was rejected to the age and sedentary worker at 0.05 level of significance.

\section{Discussion}

Orthopaedic surgery is one of the most painful surgeries because of its nature which always contains muscular and skeletal tissue reconstruction and reform ${ }^{[22]}$. Various essential oils are used as a complementary therapy in pain reduction in ortho surgical procedures. As pain and discomfort are subjective and personal feel, the researcher used the pain scale and discomfort intensity scale to measure the pain and discomfort of the patient undergoing orthopaedic surgeries. The present study findings showed that lavender oil aromatherapy has a significant impact on pain and discomfort reduction in patients who underwent orthopaedic surgeries.

The present study results were supported by results of an RCT with 82 patients undergoing orthopaedic surgery compared the changes in pain scores between the two groups showed that there is a significant relationship $(p=.049)$ between the intensity of pain in control and treatment groups with aromatherapy (essential oil of lemon) ${ }^{[23]}$ and also similar results of the present study was found in another RCT with 26 patients per group investigated the effects of aromatherapy (Eucalyptus oil inhalation) on patients who underwent a total knee replacement. The aromatherapy inhalation was effective in reducing the patient's subjective pain and blood pressure after surgery [24]. Another RCT with 60 fractured limb patients with aromatherapy showed significant changes with pain reduction but no effect on vital signs ${ }^{\text {[25] }}$.

In the similar line of the present study, there were studies showed improvements in pain reduction with aromatherapy in different populations. In quasi-experimental design with 40 arthritis patients aromatherapy significantly decreased both the pain score and the depression score of the experimental group compared with the control group ${ }^{[26]}$. A clinical trial of 50 patients with CABG showed that the pain perception intensity in the case group was lower than that in the control group with lavender essence at the 30- and 60minute phases after intervention $(\mathrm{P}<0.0001)^{[27]}$.

The present study result was not consistent with a few studies of different populations. In a clinical single-blind trial, 40 patients who had open-heart surgery in the cardiac ICU showed no significant difference and the result of the study proves that lavender essential oil inhalation does not affect reducing the pain of open-heart surgery ${ }^{[28]}$. And also in patients undergoing a breast biopsy, aromatherapy did not influence the pain but had an effect on satisfaction ${ }^{[29]}$.

Overall, the present study indicated that the orthopaedic post-operative surgical patients experience severe pain and discomfort. The result showed that using aromatherapy has a significant impact on pain and discomfort reduction. Thus aromatherapy can be used as a complementary therapy to reduce pain and discomfort. Considering the advantages of this method as an easy, inexpensive, safe, and non-invasive approach, the application of this non- pharmacological method is recommended to reduce patients' pain and discomfort within the post-operative period.

\section{Association between the pre interventional pain and discomfort with baseline and clinical variables of post-operative orthopaedic patients}

There was a significant association between gender $(t=2.7$, $\mathrm{df}=28, \mathrm{p}=0.11$ ) and post- operative pain and also sedentary worker $(t=2.485, d f=28, \quad p=0.19)$ with post-operative discomfort. There was no association found with other variables. Hence H03 was rejected to the age and sedentary worker at 0.05 level of significance.

\section{Discussion}

Orthopaedic surgery is one of the most painful surgeries because of its nature which always contains muscular and skeletal tissue reconstruction and reform.22 Various essential oils are used as a complementary therapy in pain reduction in ortho surgical procedures. As pain and discomfort are subjective and personal feel, the researcher used the pain scale and discomfort intensity scale to measure the pain and discomfort of the patient undergoing orthopaedic surgeries. The present study findings showed that lavender oil aromatherapy has a significant impact on pain and discomfort reduction in patients who underwent orthopaedic surgeries.

The present study results were supported by results of an RCT with 82 patients undergoing orthopaedic surgery compared the changes in pain scores between the two groups showed that there is a significant relationship $(p=.049)$ between the intensity of pain in control and treatment groups with aromatherapy (essential oil of lemon) 23 and also similar pharmacological method is recommended to reduce patients' pain and discomfort within the post-operative period.

\section{Conclusion}

Aromatherapy is found to be a safe, simple, and effective post-operative pain and discomfort management in orthopaedic surgical patients. 


\section{Limitations}

The study was done in a single setting. Therefore the results may not be highly representative.

\section{Competing interests}

The authors declare no conflict of interest.

\section{Acknowledgment}

The authors thank all the patients, their caregivers, the hospital authorities, the Ethics committee, and the Biostatistics department who helped to complete this study successfully

\section{References}

1. Kamal YA. Inhalational aromatherapy for postoperative pain: The disturbed evidence. Curr Res Integr Med. 2018;3(2):13-14.

2. Puntillo F, Giglio M, Varrassi G. The Routes of Administration for Acute Postoperative Pain Medication. Pain and Therpy, 2021. https://doi.org/10.1007/s401 22-021-00286-5

3. Weiser TG, Regenbogen SE, Thompson KD. An estimation of the global volume of surgery: a modelling strategy based on available data. Lancet. 2008;372:139144.

4. Chris Pasero, Margo McCaffery. Orthopaedic Postoperative Pain Management J Perianesth Nurs 2007 Jun;22(3):160-72. quiz 172-3.doi:10.1016/j. jopan.2007.02. 004.

5. https://www.researchandmarkets.com/reports/4825313/ orthopaedic-surgery-global-

trendsand?utm_source=GNDIY\&utm_medium=PressR elease\&utm_code $=68$ p2gv\&ut

m_campaign $=1285863++$ Global+Orthopaedic + Surgery + Market+Report\%2c+2017+t o+2022++Procedure+Volume+Trends+by+Type $\% 2 c+$ Country\%2c+and+Region\&ut m_exec=joca220prd

6. Kurtz S, Ong K, Lau E, Mowat F, Halpern M. Projections of primary and revision hip and knee arthroplasty in the United States from 2005 to 2030. Bone Joint Surg Am. 2007 Apr;89(4):780-5.

7. John Tetzlaff E. Treatment of Acute Pain in the Orthopaedic Patient, - A review of the mechanisms of acute pain and treatment strategies in orthopaedic patients with special emphasis on pre-emptive analgesia. PPM7 Articles in Volume 4, Issue \#4, https://www.practicalpainmanagement.com/treatments/ pharmacological/treatment- acute-pain-orthopaedicpatient)

8. English KL, Paddon-Jones D. Protecting muscle mass and function in older adults during bed rest. Curr Opin Clin Nutr Metab Care. 2010 Jan;13(1):34-9.

9. Kehlet H, Jensen TS, Woolf CJ. Persistent post surgical pain:risk factors and prevention. Lancet, 2006, pp 16181625

10. Benhamou D, Berti M, Brodner G. et al. Postoperative analgesic therapy Observational survey (PATHOS);a practice pattern study in 7 central/southern European countries. Pain, 2008;13(6):34-141

11. Chan EY, Blyth FM, Nairn L, Fransen M. Acute postoperative pain following hospital discharge after total knee arthroplasty. Osteoarthritis Cartilage. 2013 Sep;21(9):1257-63.
12. Tong J Gan Poorly controlled postoperative pain: prevalence, consequences, and prevention J Pain Res. 2017;10:2287-2298. doi: 10.2147/JPR.S144066

13. Veal FC, Bereznicki LR, Thompson AJ, Peterson GM, Orlikowski C. Subacute pain as a predictor of long-term pain following orthopaedic surgery: an Australian prospective 12 month observational cohort study. Medicine (Baltimore). 2015;94(36):e1498.

14. Hoofwijk DM, Fiddelers AA, Peters ML, et al. Prevalence and predictive factors of chronic postsurgical pain and poor global recovery 1 year after outpatient surgery. Clin J Pain. 2015;31(12):1017-1025

15. Schug SA, Palmer GM, Scott DA, Halliwell R, Trinca APM J. SE working group SE working group of the australian and New Zealand college of anaesthetists and faculty of pain medicine, acute pain management: scientific Evidence4th ed), ANZCA \& FPM, Melbourne, 2015.

16. Davood Hekmatpou, Yasaman Pourandish, Pouran Varvani Farahani, Ramin Parvizrad. The Effect of Aromatherapy with the Essential Oil of Orange on Pain and Vital Signs of Patients with Fractured Limbs Admitted to the Emergency Ward: A Randomized Clinical Trial. Indian J Palliat Care. 2017 OctDec;23(4):431-436.doi: 10.4103/IJPC.IJPC_37_17

17. Varvara Dimitriou, Paraskevi Mavridou, Adamantia Manataki, Dimitrios Damigos. The Use of Aromatherapy for Postoperative Pain Management: A Systematic Review of Randomized Controlled Trials J Perianesth Nurs. 2017 Dec;32(6):530-541. doi: 10.1016/j.jopan.2016.12.003. Epub 2017 Apr 13.)

18. Lakhan SE, Sheafer H, Tepper D. The effectiveness of aromatherapy in reducing pain. Pain Res Treat 2016;2016:8158693.

19. Scott Hollenbeck - Duke Effects of Lavender Oil on Postoperative Pain, Sleep Quality and Mood NCT03093454 https:// clinicaltrials. gov/ show/NCT03093454, 2017 | added to CENTRAL: 31 May 2018 | 2018 Issue 5

20. Bikmoradi A, Seifi Z, Poorolajal J et al. Effect of inhalation aromatherapy with lavender essential oil on stress and vital signs in patients undergoing coronary artery bypass surgery: A single-blinded randomized clinical trial. Complement Ther Med. 2015;23(3):331-8.

21. Kanani M, Mazloum SR, Emami A, Mokhber N. The effect of aromatherapy with orange essential oils on anxiety in patients undergoing hemodialysis. Q J Sabzevar Univ Med Sci. 2012;19:249-57.

22. Funda Buyukyilmaz, Asti. Postoperative pain characteristics in Turkish orthopaedic patients. Pain Manag Nurs. 2010;11(2):76-84.

23. Mahboubeh Nazari, Farhad Kamrani, Mohammad sahebalzamani, Gholam reza amin, on the investigation of the effect of aromatherapy on pain after orthopaedic surgery: clinical trial, 2016;4:1513.

24. Yang Suk Jun et al. Effect of Eucalptus oil inhalation on pain and inflammatory responses after total knee Replacement. A randomized Trial. Evidence based complementaty and alternative medicine, 2013.

25. Davood Hekmatpou, Yasaman Pourandish, Pouran Varvani Farahani, Ramin Parvizrad. The Effect of Aromatherapy with the Essential Oil of Orange on Pain and Vital Signs of Patients with Fractured Limbs Admitted to the Emergency Ward: A Randomized 
Clinical Trial Indian J Palliat Care. 2017 OctDec;23(4):431-436. doi: 10.4103/IJPC.IJPC_37_17

26. Myung-Ja Kim 1, Eun-Sook Nam, Seun-In Paik. The effects of aromatherapy on pain, depression, and life satisfaction of arthritis patients Taehan Kanho Hakhoe Chi 2005 Feb;35(1):186-94. doi: 10.4040/jkan.2005.35.1.186

27. Mohammad Ali Heidari Gorji, Om Golsum Ashrastaghi 1, Valiollah Habibi, Jamshid Yazdani Charati, Mohammad Ali Ebrahimzadeh. Mitra Ayasi The effectiveness of lavender essence on strernotomy related pain intensity after coronary artery bypass grafting Adv Biomed Res. 2015 Jun4;4:127. doi: 10.4103/2277-9175.158050. eCollection 2015

28. Armaiti Salamati et al., Effects of Inhalation of Lavender Essential Oil on Open-heart Surgery Pain. Iran J Pharm Res. 2014;13(4):1257-1261.

29. Kim JT, Wajda M, Cuff G, Serota D, Schlame M, Axelrod DM et al. Evaluation of aromatherapy in treating postoperative pain: pilot study. Pain Pract. 2006;6(4):273-277. 